\title{
PROVENIÊNCIA E IDADE DEPOSICIONAL DE SEQÜÊNCIAS METAVULCANO- SEDIMENTARES DA REGIÃO DE SANTA TEREZINHA DE GOIÁS, BASEADA EM DADOS ISOTÓPICOS SM-ND E U-PB EM MONOCRISTAL DE ZIRCÃO
}

\author{
ELTON LUIZ DANTAS, HARDY JOST, REINHARDT A. FUCK, JOSÉ AFFONSO BROD, \\ MÁRCIO MARTINS PIMENTEL \& PAULO ROBERTO MENESES
}

\begin{abstract}
PROVENANCE AND DEPOSITIONAL AGE OF METAVOLCANO-SEDIMENTARY SEQUENCES OF THE SANTA TEREZINHA DE GOIÁS, BASED ON Sm-NI AND U-Pb ZIRCON SINGLE GRAIN Supracrustal rocks of the Santa Terezinha de Goiás region, Central Brazil, presumably represent a southern extention of the Mara Rosa magmatic arc tectonically juxtaposed to Archean terrains and consist of a metavolcanic unit and a metasedimentary unit. The aim of the paper is to present and discuss the first U-Pb and Sm- $\mathrm{Nd}$ data of rocks beloging to both units of that region. U-Pb data of zircons from a felsic metavolcanic rock interlayered with chlorite-rich schists (metandesites?) yield a concordant age of of $660 \mathrm{My}$, while the $\mathrm{Sm}-\mathrm{Nd}$ model age of a variety of chlorite-schists indicate a juvenile age between 1.1 and $1.3 \mathrm{Ga}$. These data indicate that the metavolcanic rocks are Neoproterozoic in age and may be correlated with rocks of the Mara Rosa magmatic arc. On the other hand, the prevailing provenance of rocks belonging to the metasedimenary unit indicate a Paleoproterozoic, or older, source. Thus, the deposition of both units are explained by means of the erosion of source-areas of variable age.
\end{abstract}

Keywords: Nd Isotopes, U-Pb single zircon, provenance ages, magmatic arc, Proterozoic, Central Brazil

\begin{abstract}
RESUMO Rochas supracrustais da região de Santa Terezinha de Goiás presumivelmente representam extensão meridional do arco magmático de Mara Rosa tectonicamente justaposto a terrenos arqueanos e consistem de uma unidade metavulcânica e outra metassedimentar. $\mathrm{O}$ artigo visa apresentar os primeiros dados U-Pb e Sm- $\mathrm{Nd}$ de rochas daquela região. Os dados de U-Pb em zircão de rocha metavulcânica félsica interestratificada em xistos ricos em clorita (metandesitos?) geraram uma idade de $660 \mathrm{Ma}$ e os dados de idade modelo Sm-Nd de diversos outros tipos de rochas metavulcâncias indica que as mesmas são de caráter juvenil e geradas durante o intervalo entre 1.1 e $1.3 \mathrm{Ga}$. Estes dados indicam que as rochas metavulcânicas se formaram durante o Neoproterozóico e podem ser correlacionadas com arco magmático de Mara Rosa. Por outro lado, diverssas amostras da unidade metassedimentar mostram que a área-fonte era de idade predominante paleoproterozóica, ou mais velha, e indicam retrabalhamento de crosta mais antiga. Assim, a deposição destas rochas é fruto da erosão e deposição de produtos derivados de fontes de idade diversa.
\end{abstract}

Palavras-chaves: Isótopos de Nd, U-Pb em monocristal de zircões, idades de proveniência, arco magmático, Proterozóico, Brazil Central

\begin{abstract}
INTRODUÇÃO
A maioria das seqüências metavulcanosedimentares da porção central da Província Tocantins têm sido interpretadas como resultantes da evolução de um sistema de arcos-de-ilhas de idade neoproterozóica (Pimentel et al. 2000). Contudo, a idade de algumas seqüências de rochas suprarustais, como as das proximidades de Santa Terezinha de Goiás, é desconhecida e motivo de controvérsias. Estas rochas foram interpretadas como parte ora de greenstone belts arqueanos, ora como sequiências paleoproterozóicas (Ribeiro Filho 1981, Machado et al.1981, Souza \& Leão Neto 1984, Marini et al. 1984, Ribeiro Filho \& Lacerda Filho 1985, Biondi \& Piodevin 1994, Arantes et al. 1991). Mais recentemente, estas foram incluídas no arco magmático neoproterozóico de Mara Rosa (Viana 1995, Viana et al.1995, Pimentel et al. 1997, Lacerda Filho et al. 1999).

O mapeamento geológico, na escala de 1:25.000, de cerca de 820 $\mathrm{km}^{2}$ de área situada nas proximidades de Santa Terezinha de Goiás (Jost et al. 2001) abrangeu parte destas rochas (Fig. 1) e permitiu a amostragem controlada de seus principais litotipos com vistas à obtenção de dados geocronológicos. Este artigo visa divulgar os primeiros resultados isotópicos $\mathrm{Sm}-\mathrm{Nd}$ e U-Pb das amostras coletadas e discutir a sua proveniência e idade deposicional.
\end{abstract}

CONTEXTO GEOLÓGICO A área estudada situa-se no centrosul da Província Tocantins (Fig. 1), cujo contexto geológico regional abrange a porção setentrional dos terrenos arqueanos de Goiás e rochas supracrustais atribuídas ao Proterozóico (Pimentel et al. 2000). O contato entre ambos segmentos é a Zona de Cisalhamento Mandinópolis (Jost et al. 2001), de direção geral EW, com inflexão para NE no extremo leste, mergulhos moderados para quadrantes de norte e cinemática compatível com rampa frontal a lateral de falha de empurrão.

As rochas arqueanas, situadas a sul, compreendem, de oeste para leste, parte dos greenstone belts de Crixás, Guarinos e Pilar de Goiás, e associações granito-gnáissicas de parte do Complexo Caiamar e do Bloco Moquém. Dentre as rochas supracrustais arqueanas, apenas os metakomatiitos do greenstone belt de Crixás estão datados (Arndt et al. 1989) e forneceram idades isocrônicas $\mathrm{Sm}-\mathrm{Nd}$ e $\mathrm{Pb}-\mathrm{Pb}$ de $2.825 \pm$ $98 \mathrm{Ma}$ e $2.728 \pm 140 \mathrm{Ma}$, respectivamente. Isócrona Sm-Nd obtida mais recente inclui os metakomatiitos de Crixás e indicou idade mais antiga, de 3,00 $\pm 0,09 \mathrm{Ga}$ (Fortes et al. 2002). Dados isotópicos U-Pb SHRIMP de zircão e titanita de rochas dos complexos granitognáissicos da região (Queiroz 2000) registram idades magmáticas entre $2,842 \pm 6 \mathrm{Ma}$ e $2,707 \pm 4 \mathrm{Ma}$ e algumas contêm zircão herdado com idade em torno de $3.2 \mathrm{Ga}$. A titanita de alguns gnaisses registram idades de metamorfismo em $2.7 \mathrm{Ga}$ e $2.0 \mathrm{Ga}$. Apenas uma amostra de gnaisse granodiorítico do Bloco Moquém, situada próxima a um trondhjemito (Trondhjemito Santo Antônio) que intrude metabasaltos do greenstone belt de Guarinos, registrou a influência de evento mais jovem que o Paleoproterozóico, com idade U-Pb de zircão de cerca de 590 Ma. Por outro lado, as rochas proterozóicas tectonicamente sobrepostas aos terrenos arqueanos e objeto deste estudo, abrangem um conjunto complexo de supracrustais para o qual ainda não há consenso sobre seus padrões estruturais, conteúdos litológicos, nomenclatura estratigráfica, extensão, relações de contato e idades. Para a área estudada convergem, pelo menos, três unidades principais. De leste-nordeste, a literatura registra rochas agrupadas nas sequeencias Mara Rosa e Chapada, e de norte-noroeste, na Sequiência Santa Terezinha.

Ribeiro Filho (1981) descreve que a Seqüência Mara Rosa, cuja localidade tipo situa-se nas proximidades da cidade homônima, consiste de rochas metavulcano-sedimentares dispostas em faixas NNE separadas por ortognaisses, em discordância sobre os terrenos arqueanos e correlacionáveis com as seqüências de Juscelândia, Palmeirópolis e Indaianópolis. Já Machado et al. (1981), Marini et al. (1984) e Arantes et al. (1991) a interpretam como a continuidade, para norte, dos terrenos granito-greenstone belts arqueanos de Crixás-Guarinos-Pilar de Goiás. Contudo, Viana (1995), Viana et al. (1995) e Pimentel et al. (1997) mostram que as rochas da Seqüência Mara Rosa, na área-tipo, apresentam idades U-Pb em zircão e titanita e $\mathrm{Rb}-\mathrm{Sr}$ em rocha total entre $862 \pm 8$ Ma e $632 \pm 4$ Ma e assinatura geoquímica e isotópica juvenil e compatível com ambiente de arco-de-ilha intra-oceânico do Ciclo Brasiliano e estendem esta interpetação para a Seqüência 


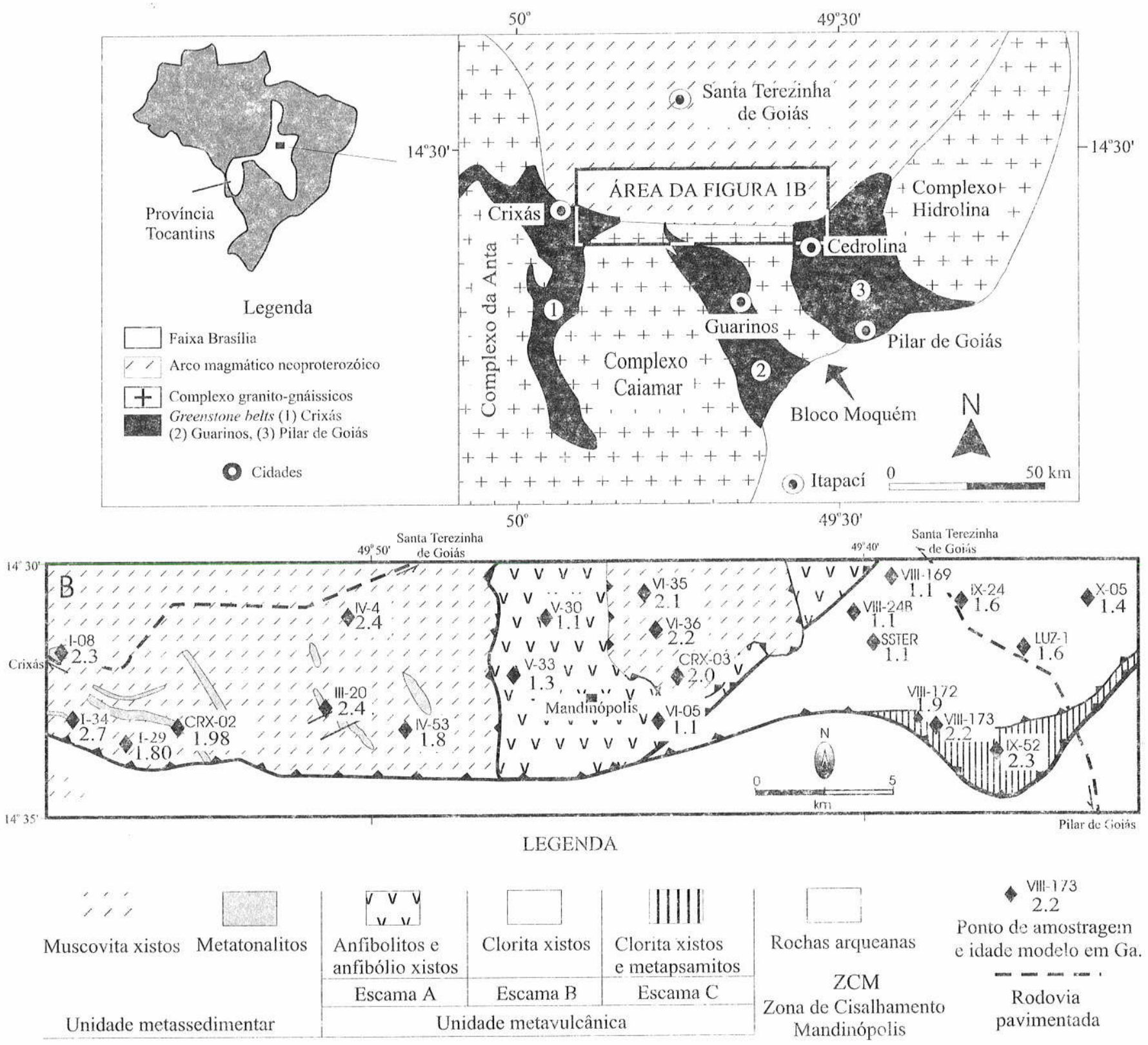

Figura I-Localização e mapa geológico simplifícado da regiãopróxima de Santa Terezinha de Goiás, entre Mandinópolis-Cedrolina, com indicaşão da posiçãoe idade das amostras analisadas.

Chapada. Por outro lado, a Seqüência Chapada, localizada a SSW da Seqüência Mara Rosa consiste, como proposto por Machado et al. (1981), de gnaisses, actinolita e talco xistos, metapelitos, xistos carbonosos e formações ferríferas correlacionáveis à porção superior dos greenstone belts. No entanto, Ribeiro Filho (1981) e Richardson et al. (1986) argumentam que a seqüência rcpousa em discordância sobre os terrenos arqueanos e a interpreta como de idade proterozóica e Kuyumjian (1989) atribui a sua formação a ambiente de arco. Viana et al. (1995) interpretam as Seqüências Mara Rosa e Chapada como produtos de um amplo sistema de arco intra-oceânico do Cicło Brasiliano.

A Seqüência Santa Terezinha, como proposta por Souza \& Leão Neto (1944) e Barros Neto (2000), consiste dominantemente de rochas metassedimentares que os autores correlacionam com a Sequiência Mara Rosa. Entretanto, Machado et al. (1981) e Biondi \& Piodevin (1994) a correlacionam com o topo dos greenstone belt de Crixás, Ribeiro Filho \& Lacerda Filho (1985) a interpretam como discordante sobre os terrenos arqueanos e Pimentel \& Fuck (1992) sugerem a sua inclusão no arco magnático de Goiás, com evolução entre 900 e 600 Ma. No mapa geológico de Goiás, recentemente publicado por
Lacerda Filho et al. (1999), as três sequiências figuram, na área estudada, sob a denominação única de Seqüência Mara Rosa.

O mapeamento em escala 1:25.000 realizado por Jost et al. (2001) revelou que as rochas do proterozóico estão em contato por falha de empurräo sobre os terrenos arqueanos e os autores as desdobran:, de modo informal, em uma unidade metassedimentar tectonicamente sobreposta por milonitos de baixo mergulho a outra metavulcênica. A unidade metassedimentar aflora na porção noroeste da área e consısto de quartzo-mica xistos (metapelitos), subordinadamente quartzitos e, localmente, imbricações tabulares de biotita xisto ỉeldspático 'intit? gnaisses interpretados como sucedâneos de tonalito. Patagêneses mi nerais das rochas desta unidade indicam metamorfisio na fácics xisto verde, zona da biotita. A unidade metavulcânica ocorre a leste da metassedimentar e consiste de, pelo menos, três escamas de empu ão que diferem em associação litológica, padrão estrutural e grau de melamorfismo. As escamas se superpõem tectonicamente de oesie pard leste (Fig. 1). A escama mais ocidental (escama A) compreende anfibólio xistos e anfibolitos derivados de derrames, intrusõcs subvulcânicas e rochas epiclásticas metamorfisadas na fácies anfibolito. A cscama B compreende clorita xistos e magnetita-clorita 
xistos, subordinadamente granada-biotita gnaisses e gnaisses quartzofeldspáticos, cujos protólitos são prováveis tufos andesíticos a dacíticos e/ou riolíticos metamorfisados na fácies xisto verde. A escama C consiste de clorita xistos, prováveis tufos andesíticos c epiclásticas, com intercalações subordinadas de quartzito e metarritmito, da fácies xisto verde.

\section{AMOSTRAGEM E CARACTERÍSTICAS PETROGRÁFICAS}

A amostragem com vistas às determinações geocrológicas e de proveniência das rochas supracrustais intepretadas como proterozóicas c situadas imediatamente a norte dos terrenos arqueanos da região mapeada por Jost et al. (2001) abrangeu uma coleta sistemática de rochas da unidade metassedimentar e das três escamas de empurrão da unidade metavulcânica. Do total de 23 amostras analisadas, 10 provêm da unidade metassedimentar e 13 da metavulcânica, das quais 2 da escama A, 7 da escama B e 4 da escama C (Fig. 1, Tabela 1).

Da unidade metassedimentar, as amostras de quartzo-mica xisto são de granulação grossa e consistem de quarzto, biotita e fengita, clorita e opacos e são intepretados como metapelitos. As de metatonalito são compostas de quartzo, albita-oligoclásio e biotita, subordinadamente microclínio, clorita, granada, zircão, titanita, epidoto e opacos.

Dentre as rochas da unidade metavulcânica, os anfibólio xistos diagnósticos da escama A são compostos por hornblenda, oligoclásio, fengita, quartzo, biotita e clinozoizita, localmente augita e feldspato potássico, e os anfibolitos por hornblenda e andesina-labradorita, subordinadamente opacos e titatina. Granada e hornblenda constituem fenoblastos de até $2 \mathrm{~cm}$. Nas escamas B e C, as rochas predominantes compreendem clorita xistos compostos por clorita, biotita, quartzo, albita, fengita, subordinadamente cloritóide, magnetita, granada e clinozoizita e provavelmente derivam de tufos andesíticos. Os clorita xistos localmente apresentam intercalações de gnaisses finos compostos de quarzto, biotita, microclínio, plagioclásio e turmalina, subordinadamente, granada, muscovita, zircão, epidoto e magnetita e provavelmente representam vulcânicas dacíticas a rioltícias. Na escama C, os clorita xistos contém intercalaçôes de quartzitos brancos a cinza e metaritmitos, ausentes na escama B. Estas rochas são, em geral, ricas em quartzo, biotita, fengita e opacos.

MÉTODOS ANALÍTICOS E RESULTADOS As amostras foram analisadas no Laboratório de Geocronologia da Universidade de Brasília. As análises pelo método $\mathrm{Sm}-\mathrm{Nd}$ seguiram os procedimentos descritos por Gioia \& Pimentel (2000) e as pelo método U-Pb os propostos por Parrish (1987) e Krogh (1973), adaptados às condições do Laboratório de Geocronologia da UnB, e representam as primeiras análises em zircões individuais realizadas no mesmo. Antes da dissolução do zircão, adiciona-se a cada amostra uma solução do traçador (spike) ${ }^{205} \mathrm{~Pb}^{235} \mathrm{U}$. As medidas isotópicas são feitas em espectrômetro de massa tipo Finnigan MAT 262 nos módulos de coletor individual e múltiplos. As composições isotópicas de $\mathrm{Pb}$ e U são analisadas em filamentos individuais de Rênio usando sílica gel e ácido fosfórico e corrigidas pela média obtida no padrão de Pb comum SRM 981. O fracionamento de Urânio é monitorado pela replica de análises do padrão SM 500. Incertezas na razão U-Pb decorrentes da espectrometria de massa e do fracionamento são na ordem de $0.5 \%$. Isótopos de $\mathrm{Pb}$ radiogênico são calculados pela correção para os brancos analíticos de $\mathrm{Pb}$ e para $\mathrm{Pb}$ original não radiogênico correspondente ao model de $\mathrm{Pb}$ de Stancey \& Kramers (1975) em relação a idade apropriada da amostra. Incertezas na razão de $\mathrm{Pb}$ radiogênico são tipicamente em torno de $0.1 \%$, salvo em casos em que a amostra tenha baixa razão ${ }^{206} \mathrm{~Pb} /{ }^{204} \mathrm{~Pb}$, onde podem ser maiores. A constante de decaimento empregadas são propostas por Steige \& Jager (1977) e o total do branco de procedimento durante as análises são da ordem de $10-50$ pg para $\mathrm{Pb}$ e de 0.5 1 pg para U. Os dados obtidos na analise dos zircões são tratados no programa ISOPLOT de Ludwing (1999), e as incertezas nas idades em relação ao intercepto da concórdia são da ordem de 2 sigma.

Os resultados das determinações isotópicas de $\mathrm{Sm}-\mathrm{Nd}$ nas rochas da região revelam grande variação das idades modelo $\mathrm{T}_{\mathrm{DM}}$ (Tabela $1 \mathrm{e}$ Fig. 1). Amostras da unidade metassedimentar geraram idades modelo $\mathrm{T}_{\mathrm{DM}}$ entre $2,4 \mathrm{Ga}$ e 1,8 Ga, o que sugere proveniência a partir de áreafonte paleoproterozóica ou, alternativamente, mistura entre rochas arqueanas e fontes mais jovens indeterminadas. Amostras de lentes de metatonalitos forneceram idades modelo $\mathrm{T}_{\mathrm{DM}}$ de $2.7 \mathrm{Ga}$ a $2.4 \mathrm{Ga}$ e valores $\varepsilon_{N d}(0)$ extremamente negativos, sugestivos de derivação por fusão de fontes continentais retrabalhadas.

Dentre as amostras da unidade metavulcânica, as coletadas nas escamas A e B apresentam assinatura isotópica típica de rochas de ambiente de arco juvenil, com idades modelo $\mathrm{T}_{\mathrm{DM}}$ entre $1.3 \mathrm{Ga}$ e $1.1 \mathrm{Ga}$ e valores de $\varepsilon_{\mathrm{Nd}}(\mathrm{t})$ positivos (Tabela $1 \mathrm{e}$ Fig. 2 ), semelhantes às obtidas por Pimentel et al. (1997) na Seqüencia Mara Rosa. Entretanto, nas escamas B e C, algumas rochas terrígenas intercaladas nas metavulcânicas aparentam derivar de áreas-fonte distintas, tendo em vista que suas idades modelo $\mathrm{T}_{\mathrm{DM}}$ situam-se entre $2,2 \mathrm{Ga}$ e 1,6 Ga, sugestivas de contribuição a partir de crosta mais antiga. Valores positivos e negativos de $\varepsilon_{\mathrm{Nd}}$ (t) são coerentes com este quadro.

Duas amostras de rochas metavulcânicas da escama B foram selecionadas para datação pelo método U-Pb em zircão. Uma (amostra SSTER) consiste de granada-gnaisse intercalado em clorita-xisto, c outra (amostra VIII-169) de gnaisse quartzo-feldspático intercalado em clorita-magnetita xisto. A primeira contém três populações distintas de zircão. Uma compreende cristais prismáticos, não magnéticos, límpidos e rosados, ao passo que outra ocorre como prismas curtos, euédricos e incolores, e a terceira é representada por fragmentos de cristais incolores. O conjunto destas frações se alinha em diagrama discórdia com idade do intercepto superior de cerca de $2.3 \mathrm{Ga}$ e do inferior em $630 \mathrm{Ma}$ (Fig. 3a). Entretanto, se consideradas como populações independentes, estas populações refletem heranças de diferentes fontes com idades de $700 \mathrm{Ma}, 800 \mathrm{Ma}, 1400,2.200$ e $2.400 \mathrm{Ma}$ (Fig. 3a). Este comportamento denota derivação tanto de rochas de embasamento mais antigo quanto do próprio arco magmático. Por outro lado, a idade de cristalização ígnea da rocha pode ser estimada pelo resultado fornecido pela população de zircões prismáticos, claros e rosados, com composição isotópica quase concordante de $661+8 \mathrm{Ma}$ (Fig.3b). Na amostra de gnaisse quartzo-feldspático, apenas dois cristais de zircão morfologicamente distintos foram analisados. Sua composição isotópica define intercepto superior em 2.394 Ma e inferior em $645 \mathrm{Ma}$, não mostrado em diagrama, (mas que figuram na Tabela 2). O baixo grau metamórfico da amostra suporta a interpretação de que a idade dada pelo intercepto inferior é a de cristalização do protólito vulcânico e, a do superior, componente herdada de fonte paleoproterozóica.

Em face dos resultados obtidos, o vulcanismo registrado nas rochas supracrustais expostas ao sul de Santa Terezinha de Goiás têm idade estima em 660 Ma. Em conseqüência, as seqüência de que faz parte é de idade neoproterozóica, sendo, porém, consideravelmente mais jovem do que Seqüência Mara Rosa, datada em cerca de 860 Ma (Pimentel et al. 1997).

DISCUSSÃO E CONCLUSÕES O mapeamento geológico realizado na área estudada (Jost el al. 2001) mostra que os terrenos arqueanos da região de Crixás são transversalmente secionados pela Zona de Cisalhamento de Mandinópolis e que esta estrutura é uma rampa frontal a lateral de uma falha de empurrão de vergência sul-sudeste. Ao longo da zona de cisalhamento, os terrenos granitogreenstone belts estão sotopostos a duas unidades proterozóicas litologicamente distintas. Dentre estas, a metassedimentar repousa tectonicamente sobre a metavulcânica, por sua vez, desmembrada em pelo menos três escamas de empurrão que contrastam em fácies metamórfica, associação litológica e detalhes estruturais. A estas diferenças se somam, também, distintas assinaturas isotópicas.

Os resultados isotópicos mostram que os protólitos da unidade metassedimentar foram depositados a partir da erosão de uma áreafonte composta por litotipos mais antigos. Os valores de $\mathrm{T}_{\mathrm{DM}}$ oferecem um amplo espectro de idades modelo, mas a contribuição sedimentar mais significativa é fruto ou da erosão de crosta paleoproterozóica ou da mistura de detritos arqueanos e neoproterozóicos. A presença de zircão com idade de 2,4 Ga na unidade metavulcânica não descarta a participação de crosta siálica mais antiga, talvez do embasamento da Faixa Brasília situado a nordeste da área estudada (Fuck et al. 2001).

Entretanto, a idade da sedimentação da unidade metassedimentar é ainda incerta, pois, em rochas desta natureza, o método $\mathrm{Sm} / \mathrm{Nd}$ tem a 
capacidade apenas de registrar uma idade modelo cujo valor resulta da mistura de cargas clásticas de idades diversas, mas pode denunciar a participação de áreas-fonte antigas (Dickin 1995). Assim, idades modelo $T_{D M}$ calculadas para rochas sedimentares a partir de valores do manto empobrecido (DePaolo 1981), não representam um único evento de formação de crosta. Estas idades refletem o tempo médio de residência crustal das rochas da área-fonte dos sedimentos, mas não a idade estratigráfica dos mesmos.

Por semelhança litológica, a unidade metassedimentar pode ser correlacionada com a Seqüência Santa Terezinha, na qual Biondi \& Piodesin (1994) obtiveram idade $\mathrm{Pb} / \mathrm{Pb}$ de $2.690 \mathrm{Ma}$ em rocha total e entre $700 \mathrm{Ma}$ e $800 \mathrm{Ma}$ em albita e carbonato de depósitos de esmeralda. Por sua vez, Barros Neto (2000) obteve idades modelo $T_{\text {DM }}$ entre 1,3 Ga e 1,6 Ga em rochas metassedimentares da região de Campos Verdes, sugerindo que houve contribuição de fonte jovem para a car-

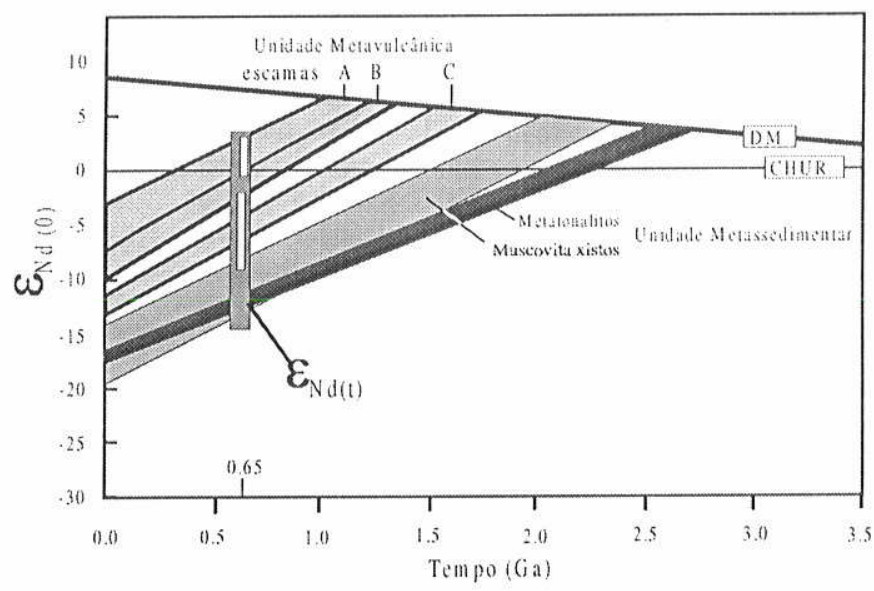

Figura 2 - Diagrama deevolução isotópica de Nd mostrando o comportamento distinto entre a unidade metassedimentar e metavulcânica e, neste, das diferentes escamas de emparrão. ga de detritos sedimentares. Estes resultados são coerentes com os de Pimentel et al. (2001) de que grande parte das rochas metassedimentares da Faixa Brasília deriva de fontes distintas.

Por outro lado, os dados isotópicos $\mathrm{Sm}-\mathrm{Nd}$ da unidade metavulcânica indicam que esta é primitiva e de idade modelo T $T_{\text {DM }}$ entre $1.1 \mathrm{Ga}$ e $1.3 \mathrm{Ga}$. Apenas as poucas rochas metassedimentares intercaladas nas metavulcânicas evidenciam a participação de fontes relacionadas com crosta continental mais antiga, como registra a presença de cristais de zircão com amplo espectro de idades herdadas. Estes dados são compatíveis com os obtidos por Pimentel et al. (1993), Viana \& Pimentel (1994), Viana (1995), Viana et al. (1995) e Junges (1998) em rochas metassedimentares, metavulcânicas e ortognaisses da região-tipo da Seqüência Mara Rosa e os de Richardson et al. (1986) na região-tipo da Seqüência Chapada. Por conseguinte, interpretamos a unidade metavulcânica da área mapeada por Jost et al. (2001) como parte de ambiente do arco magmático de idade neoproterozóica (Pimentel et al. 1997). Entretanto, o conjunto de dados apresentados indica que a melhor estimativa da idade do vulcanismo da região é da ordem de 630-660 Ma, a qual, comparativamente aos dados geocronológicos de outras áreas do arco magmático de Goiás (» 800 Ma) difere em cerca de $200 \mathrm{Ma}$, não sendo, portanto, como conclusão mais significativa decorrente dos dados geocronológicos, estratigraficamente correlacionável ao da Seqüência Mara Rosa. Adicionalmente, considerando que a unidade metassedimentar e a metavulcânica são alóctones e que, em ambas, o transporte tectônico ocorreu após a principal fase de deformação e metamorfismo, a zona de descolamento entre estas e os terresnos arqueanos, representada pela Zona de Cisalhamento Mandinópolis, também é neoproterozóica e se formou ao fïnal do Ciclo Brasiliano.

Agradecimentos À Universidade de Brasília pelo suporte financeiro aos trabalhos de campo, ao Conselho Nacional de Desenvolvimento Cientílico e Tecnológico - CNPq pelo suporte aos trabalhos de laboratório (processo 46.048/00) e pelas Bolsas de Produtividade a $\mathrm{H}$. Jost, R. A Fuck e M. M. Pimentel e a dois revisores anônimos da RBG pelas sugestões ao original.

Tabela I - Resultados de determinações isotópicas Sm-Nd de rochas das unidades supracrustais de Santa Terezinha de Goiás.

\begin{tabular}{|c|c|c|c|c|c|c|c|c|}
\hline Amostra & $\begin{array}{l}\text { Localização } \\
\text { (UTM) }\end{array}$ & Rocha & Nd (ppm) & $\begin{array}{c}\mathrm{Sm} \\
(\mathrm{ppm})\end{array}$ & ${ }^{1+7} \mathrm{Sm} /{ }^{14+} \mathrm{Nd}$ & $\begin{array}{c}{ }^{1+3} \mathrm{Nd} /{ }^{1+4} \mathrm{Nd} \\
(2 \sigma)\end{array}$ & $\varepsilon_{\mathrm{Nd}}(0)$ & $\begin{array}{l}\mathrm{T}_{\mathrm{DM}} \\
(\mathrm{Ma})\end{array}$ \\
\hline \multicolumn{9}{|c|}{ UNIDADE METASSEDIMENTAR } \\
\hline $\mathrm{I}-08$ & $0614418-8393328$ & Metatonalito & 32.74 & 6.97 & 0.1287 & $0.511755(29)$ & -17.22 & 2.300 \\
\hline $\mathrm{I}-34$ & $0613841-8391326$ & Metatonalito & 20.88 & 4.03 & 0.1175 & $0.511252(41)$ & -27.04 & 2.700 \\
\hline $\mathrm{I}-29$ & $0613910-8392807$ & Muscovita xisto & 22.89 & 4.20 & 0.1109 & $0.511805(30)$ & -16.24 & 1.822 \\
\hline CRX-02 & $0619031-8390731$ & Muscovita xisto & 44.08 & 8.63 & 0.1185 & $0.511794(20)$ & -16.47 & 1.985 \\
\hline III-20 & $0623907-8393292$ & Metatonalito & 38.56 & 8.59 & 0.1348 & $0.511771(25)$ & -16.91 & 2.450 \\
\hline IV -53 & $0626512-8391805$ & Biotita Xisto & 57.79 & 10.29 & 0.1082 & $0.511748(9)$ & -17.35 & 1.824 \\
\hline IV -4 & $0625560-8395335$ & Muscovita xisto & 3.87 & 0.92 & 0.1454 & $0.511884(04)$ & -14.71 & 2.435 \\
\hline VI-35 & $0635925-8394736$ & Muscovita xisto & 19.82 & 4.46 & 0.1368 & $0.511915(10)$ & -14.09 & 2.136 \\
\hline VII-36 & $0638813-8392199$ & Muscovita xisto & 134.44 & 25.06 & 0.1157 & $0.511572(36)$ & -20.8 & 2.203 \\
\hline CRX-3 & $0639452-8391042$ & Muscovita xisto & 119.78 & 28.63 & 0.1445 & $0.512106(13)$ & -10.37 & 2.047 \\
\hline \multicolumn{9}{|c|}{ UNIDADE METAVULCÂNICA } \\
\hline \multicolumn{9}{|c|}{ ESCAMA A } \\
\hline $\mathrm{V}-30$ & $0631666-8392198$ & Amfibolio xisto & 14.46 & 3.13 & 0.1309 & $0.512393(27)$ & -4.77 & 1.168 \\
\hline $\mathrm{V}-33$ & $0631415-8393216$ & Amfibolio xisto & 14.56 & 3.24 & 0.1345 & $0.512357(27)$ & -5.48 & 1.308 \\
\hline VI-05 & $0635591-8392177$ & Clorita xisto & 4.61 & 1.20 & 0.1591 & $0.512650(15)$ & 0.15 & 1.125 \\
\hline \multicolumn{9}{|c|}{ ESCAMA B } \\
\hline IX-24 & $0646675-8396050$ & Clorita xisto & 44.97 & 9.24 & 0.1243 & $0.512103(16)$ & -10.43 & 1.588 \\
\hline LUZ-I & $0652679-8399485$ & Clorita xisto & 13.09 & 2.50 & 0.1156 & $0.511974(28)$ & -12.95 & 1.648 \\
\hline $\mathrm{X}-05$ & $0654552-8395510$ & Gnaisse & 14.61 & 3.20 & 0.1325 & $0.512283(23)$ & -6.93 & 1.414 \\
\hline SSTER & $0645244-8391530$ & Granada gnaisse & 130.61 & 24.73 & 0.1145 & $0.512305(15)$ & -6.49 & 1.128 \\
\hline VIII-24B & $0645244-8391530$ & Biotita gnaisse & 171.15 & 28.72 & 0.1020 & $0.512230(14)$ & -7.97 & 1.123 \\
\hline VIII-169 & $0644472-8396030$ & Biotita gnaisse & 181.61 & 33.93 & 0.1130 & $0.512308(10)$ & -6.43 & 1.106 \\
\hline \multicolumn{9}{|c|}{ ESCAMA C } \\
\hline VIII-172 & $0645271-8391727$ & Metaepiclastica & 33.45 & 6.58 & 0.1197 & $0.511787(34)$ & -16.59 & 1.970 \\
\hline VIII-173 & $0645309-8391864$ & Metaepiclastica & 22.11 & 4.12 & 0.1128 & $0.511571(19)$ & -20.82 & 2.212 \\
\hline IX-52 & $0649575-8390175$ & Quartzito & 14.71 & 2.77 & 0.1147 & $0.511499(19)$ & -22.23 & 2.285 \\
\hline
\end{tabular}



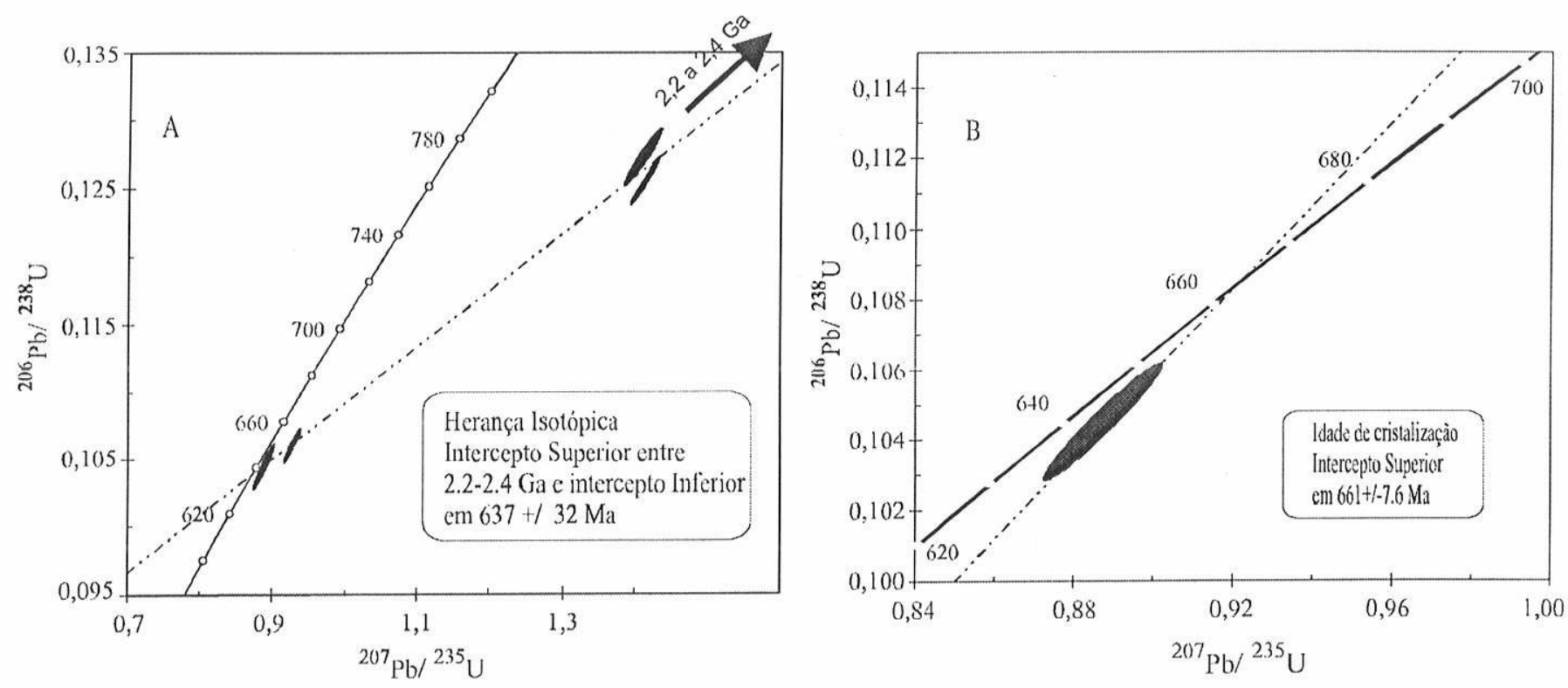

Figura 3 - Diagramas discórdia U-Pb da amostra de rocha metavulcânica (SSTER) da escama B. (A) - as diferentes populações de zircão mostram grande espalhamento no diagrama e definem dois interceptos com significado geológico. Pontos próximos do intercepto superior definem idade entre 2.2 e 2.4 Ga. A maioria dos pontos situa-se próximo do intercepto inferior com idade em cerca de 630 Ma. (B) - Detalhe mostrando populą̧ão de zircão com intercepto superior concordante em $660 \mathrm{Ma}$.

Tabela 2 - Dados isotópicos de U-Pb em zircões de rochas metavulcânicas félsicas da escama B da unidade metavulcânica de Santa Terezinha de Goiás.

\begin{tabular}{|c|c|c|c|c|c|c|c|c|c|c|c|c|c|c|}
\hline & & \multicolumn{2}{|c|}{ Concentração (2) } & Obs (3) & & \multicolumn{3}{|c|}{ Razão Isotópica radiogênica } & & & & \multicolumn{3}{|c|}{ Idades } \\
\hline $\begin{array}{c}\text { Amostra } \\
\text { Fração (1) }\end{array}$ & $\begin{array}{c}\text { Tamanho } \\
\text { (mg) }\end{array}$ & \begin{tabular}{c|}
$\mathrm{U}$ \\
$\mathrm{ppm}$
\end{tabular} & $\begin{array}{c}\mathrm{Pb} \\
\mathrm{ppm}\end{array}$ & $\begin{array}{l}\mathrm{Pb} 206 \\
\mathrm{~Pb} 204\end{array}$ & $\begin{array}{l}\text { Pb207* } \\
\text { U235 }\end{array}$ & $\%$ & $\begin{array}{l}\mathrm{Pb} 206^{*} \\
\text { U238 }\end{array}$ & $\%$ & $\begin{array}{l}\text { Coef. } \\
\text { Correl }\end{array}$ & $\begin{array}{l}\text { Pb207* } \\
\text { Pb206** }\end{array}$ & $\%$ & $\begin{array}{l}\mathrm{Pb} 206 * \\
\text { U238 }\end{array}$ & U23.5 & $\begin{array}{l}\mathrm{Pb} 207^{*} \\
\mathrm{~Pb} 206^{*}\end{array}$ \\
\hline \multicolumn{15}{|c|}{ Amostra SSTER } \\
\hline P, p,cl, ac & 0,018 & 230 & 25,41 & 679 & 0,92831 & 0,99 & 0,106206 & 0,96 & 0,971 & 0,063394 & 0,23 & 651 & 667 & 721 \\
\hline $\mathrm{T}, \mathrm{L}, \mathrm{cl}, \mathrm{p}, \mathrm{r}$ & 0,037 & 193 & 23 & 1862 & 1,50208 & 0,95 & 0,119063 & 0,93 & 0,986 & 0,091499 & 0,15 & 725 & 931 & 1457 \\
\hline $\mathrm{R}, \mathrm{Lcl}, \mathrm{r}$ & 0,058 & 189 & 18,96 & 1398 & 0,88769 & 1,38 & 0,104462 & 1,33 & 0,965 & 0,061631 & 0,35 & 640 & 646 & 662 \\
\hline C, peq, cl, i & 0,005 & 2137 & 315 & 305 & 1,40907 & 1,16 & 0,127201 & 1,12 & 0,966 & 0,080341 & 0,29 & 771 & 892 & 1205 \\
\hline $\mathrm{l}, \mathrm{cl}$, inc, $\mathrm{p}$ & 0,01 & 2987 & 897 & 1332 & 4,69706 & 1,63 & 0,288648 & 1,63 & 0,999 & 0,11802 & 0,02 & 1634 & 1766 & 1926 \\
\hline $\mathrm{A}, \mathrm{cl}, \mathrm{i}, \mathrm{pr}$ & 0,005 & 1185 & 213 & 297 & 3,02129 & 1,16 & 0,144916 & 1,13 & 0,971 & 0,151208 & 0,27 & 872 & 1413 & 2359 \\
\hline B, peq,cl,i & 0,008 & 706 & 89 & 238 & 0,94378 & 1,76 & 0,103133 & 1,55 & 0,887 & 0,06637 & 0,81 & 632 & 674 & 818 \\
\hline \multicolumn{15}{|c|}{ Amostra VIII-169 } \\
\hline $\mathrm{M}, \mathrm{cl}, \mathrm{in}, \mathrm{pr}$ & 0,005 & 388,6 & 57,48 & 305,5 & 1,41357 & 1,09 & 0,125538 & 1,08 & 0,988 & 0,081666 & 0,16 & 762 & 895 & 1237 \\
\hline $\mathrm{O}, \mathrm{L}, \mathrm{cl}, \mathrm{p}$, & 0,006 & 91,56 & 44,81 & 490,5 & 8,87809 & 1,15 & 0,411225 & 1,13 & 0,985 & 0,156581 & 0,19 & 2220 & 2325 & 2419 \\
\hline
\end{tabular}

(1) - $\mathrm{P}=$ microcápsula usada na dissolução, $\mathrm{p}=$ cristais prismáticos, $\mathrm{cl}=$ claros, $\mathrm{C}=$ curtos, $\mathrm{L}=$ longos, $\mathrm{R}=$ rosados, $\mathrm{T}=$ translúlido, $\mathrm{i}=$ incolor, peq $=$ pequenos. (2) Correção total do U e Pb pelo branco analítico. (3) - Pb radiogênico não corrigido por branco analítico. (4) - Pb radiogênico corrigido por branco analítico e Pb inicial; $\mathrm{U}$ corrigido. (5) - Idades em Ma calculadas com as constantes de decaimento recomendadas por Steiger \& Jager (1976).

\section{Referências}

Arantes D., Osborne G.A.. Buck P.S., Porto C.G. 1991. The Mara Rosa volcanosedimentary sequence and associated gold mineralization. In: E. Ladeira (editor) Brazil Gold '91. Balkema, Rotterdam, pp.: 221-119

Barros Neto L.S. 2000. Evoluçâo estrutural do distrito esmeraldifero de Campos Verdes. Goiás. Dissertação de Mestrado, Instituto de Geociências, Universidade de Brasília, $111 \mathrm{pp}$.

Biondi J.C. \& Poidevin J.L. 1994. Idade da mineralização e da Sequência Santa Terezinha (Goiás-Br). In: SBG, Congresso Brasileiro de Geologia, 36, Camboriú, Resumos Expandidos, 1: 302-304.

DePaolo D. J. 1981. A neodymium and strontium isotopic study of the Mesozoic calcalkaline granitic batholithys of the Sierra Nevada and Peninsular Ranges, California. Journal of Geophysical Research, 86:10470-10488.

Dickin A P. 1995. Radiogenic Isotope Geology: Cambridge University PressNew York, $452 \mathrm{p}$.

Fortes P.T.F.O, Pimentel M.M., Santos R.V., Jost H. 2002. New Sm-Nd data for metassedimentary and komatiitic rocks of the Crixás greenstone belt, central Brazil implications for the age of the upper sedimentary unit. Jour: South Am. Earth Sciences (submetido)
Fuck R.A. Dantas E.L. Pimentel M.M.. Junges S.L., Moraes R. 2001. Nd isotopes. U-Pb single grain and SHRIMP zircon ages from basement rocks of the Tocantins Province. In: South American Symposium on Isotope Geology, 3, Pucon. Chile. Proceedings, pp. 3|1-313

Gioia S.M.C.L. \& Pimentel M.M. 2000. The Sm-Nd isotopic method in the Geochronology Laboratory of the University of Brasília. Anais da Academia Brasileira de Ciências, 72:219-245

Jost H., Fuck R.A., Brod J.A., Dantas E.L., Meneses P.R, Assad M.L.L., Pimentel M.M., Blum M.L.B., A.M. Silva, Spigolon A.L.D., Maas M.V.R., Souza M.M., Fernadez B.P. Faulstich F.R.L., Macedo Júnior P.M., Schobbenhaus C.N., Almeida L.. Silva A.A.C., Anjos C.W.D., Santos A.P.M.T., Bubenick A.N., A.A.A Teixeira, Lima B.E.M., Campos M. ${ }^{\circ}$, Barjud R.M., Carvalho D.R., Scislewski L.R., Sarli C.L.. Oliveira D.P.L. 2001. Geologia de terrenos arqueanos e proterozóicos da região de Crixás-Cedrolina, Goiás. Revista Brasileira de Geociências. 31

Junges S.L. 1998. Caracterização geoquímica e isotópica de Faixa Oeste da secquência vulcanossedimentar de Mara Rosa. Dissertação de Mestrado, Instituto de Geociências, Universidade de Brasília,. $111 \mathrm{p}$.

Krough T E 1973. A low contamination method for hydrothermal decomposition of zircon and extraction of $\mathrm{U}$ and $\mathrm{Pb}$ for isotope age determination. Geochem. Cosmochim. Acta, 37:485-494. 
Kuyumjian R.M. 1989. Geoquímica e significado do posicionamento geotectônico de rochas plutônicas da regiäo de Chapada, Goiás, Brasil. In SBG: Cong. Bras. Geol., 33, Rio de Jeaneiro, Anais, pp.: 195-201

Lacerda Filho J.V., Rezende A., Silva A. 1999. Geologia e recursos minerais do Estado de Goiás e Distrito Federal. Programa Levantamentos Geológicos Básicos do Brasil. CPRM/METAGO/UnB, Goiânia. Mapa geológico e de recursos minerais, escala 500000 .

Machado E.C., Souza C.J.M., Silva M.A., Berbert C.A. 1981. Projeto Porangatu. Relatório Final, Etapa il. DNPM/CPRM, 1, 246 pgs.

Marini O.J. Fuck R.A. Danni J C.M. Dardenne M.A. Logércio S.O.C. Ramalho R. 198 As faixas de dobramento Brasília, Uruaçu e Paraguai-Araguaia e o maciço Mediano de Goiás. In: C. Schobbenhaus Filho, D.A. Campos, G.R. Derzy, H.E. Asmsus (edit.) Geologia do Brasil - Texto explicativo do mapa geológico do Brasil e da area oceânica adjacente incluindo depósitos minerais, 1:2.500.000. MME/DNPM, Brasília, pp. 251-303

Parrish R R 1987. An Improved micro-capsule for zircon dissolution in U-Pb geochronology. Chemical Geology 66, 99-102

Pimentel M.M., Fuck R.A. Machado N.. Ribeiro R.K., Viana M.G.. 1993. Dados geocronológicos U-Pb preliminares da região de Mara Rosa, Gioiás: implicações para a época de mineralização de Au e para a evolução tectônica neoproterozóica no Centro - Oeste. In: SBGq, Congresso Brasileiro de Geoquímica 4, Brasília, Volume de Resumos Expandidos, pp. 255-258.

Pimentei M.M., Dardenne M.A., Fuck R.A., Viana M.G., Junges S.L., Fischel D., Seer H.J. Dantas E,L. 2001. Nd isotopes and provenance of detrital sediments of the Neoproterozoic Brasília Belt, Central Brazil. Journal of South American Earth Sciences. 14:571-585

Pimentel M.M. \& Fuck R.A. 1992. Neoproterozoic crustal accretion in Central Brazil. Goolog, 20:375-379

Pimentel M.M., Fuck R.A., Jost H., Ferreira Filho C.F., Araújo S.M. 2000. The basement of the Brasília Fold Belt and Goiás Magmatic Arc. In: U.G. Cordani, E.J. Milani, A Fhomaz Filho, D.A. Campos (ediores) Tectonic Evolution of South America. $31^{\text {s }}$ International Geological Congress, pp.:195-230
Pimentel M.M., Whitehouse M.J., Vianna M.G., Fuck R.A., Machado N. 1997. The Mara Rosa are in the the Tocantins Province: further evidence for Neoproterozoic crustal accretion in central Brazil. Precambrian Research, 81:299-310

Queiroz C.L. 2000. Evoluçäo tectono-estrutural dos terrenos granito-greenstone belt de Crixcis, Brasil Central. Tese de Doutorado, Instituto de Geociências,

Ribeiro Filho W. \& Lacerda Filho W. 1985. Geologia da regiāo de Santa Terezinha de Goiás. In: SBG, Simp. Geol. Centro-Oeste, 2, Goiânia, pp.: 174-183

Ribeiro Filho W. 1981. Reavaliação da geologia de Pilar-Mara Rosa. In: SBG, Simpósio de Geologia do Centro-Oeste, 1, Goiânia, Atas, 281-299.

Richardson S. V., Kessler S.E., Essene E.J., Jones L.M. 1986. Origin and geochemistry of the Chapada Cu-Au deposit, Goiás, Brazil: a metamorphosed wall-rock porphyryCopper deposit. Economic Geology', 81:1884-1898

Souza J.O. \& Leão Neto R. 1984. Projeto estudo dos garimpos brasileiros: mapeamento geológico da área do garimpo de esmeralda de Santa Terezinha de Goiás, GO. Relatório Preliminar. DNPM/CPRM, Goiânia

Viana M.C. 1995. Gencronologia e geoquimica das rochas ontognáissicas e méavalcânicas dá regiäo de Mara Rosa, Go Iniversidade de Brasília, Instituto de Geociências, Dissertação de mestrado, 118 pp.

Viana M.G. \& Pimentel M. M. 1994. Dados geoquímicos e isotópicos Sm-Nd preliminares para rochas metavulcânicas e metaplutônicas da região de Mara Rosa. In: IV Simp. Geol. Centro-Oeste, Brasília, Anais, pp: $148-150$.

Viana M.G., Pimentel M.M., Whitehouse M.J., Fuck R.A., Machado N. 1995. O Arco Magmático de Mara Rosá, Goiás: dados geoquímicos e geocronológicos e suas implicações regionais. Revista Brasileira de Geociências, 25:111-123

Manuscrito 120

Recebido em 10 de janeiro de 2001

Revisão dos autores em 30 de agosto de 2001 Revisão accita cm 5 de setemiro de 2001 